\title{
Comparative Meta-Analysis and Experimental Kinetic Investigation of Column and Batch Bottle Microcosm Treatability Studies Informing In Situ Groundwater Remedial Design
}

Erin M. Driver ${ }^{\mathrm{a}}$, Jeff Roberts ${ }^{\mathrm{b}}$, Peter Dollar ${ }^{\mathrm{b}}$, Maurissa Charles ${ }^{\mathrm{a}}$, Paul Hurst ${ }^{\mathrm{c}}$, Rolf U. Halden ${ }^{\mathrm{a}, *}$

${ }^{a}$ Center for Environmental Security, The Biodesign Institute and Global Security Initiative, Arizona State University, 781 E. Terrace Mall, Tempe, AZ 85287-5904

${ }^{\mathrm{b}}$ SiREM, 130 Research Lane, Suite 2, Guelph, Ontario, Canada, N1G 5G3

${ }^{\mathrm{c}}$ Golder Associates Ltd. 1931 Robertson Road, Ottawa, Ontario, Canada, K2H 5B7

*Corresponding author at: Center for Environmental Security, The Biodesign Institute, Arizona State University, PO Box 875904, Tempe, AZ 85287-5904, USA. Tel.: +1 480727 0893; Fax: +1 480727 0889; E-mail: halden@asu.edu

Keywords: Treatability Studies; Continuous-Flow Columns; Batch Bottles; Kinetics; Perchloroethylene 


\begin{abstract}
A systematic comparison was performed between batch bottle and continuous-flow column microcosms (BMs and CMs, respectively) commonly used for in situ groundwater remedial design. Review of recent literature (2000-2014) showed a preference for reporting batch kinetics, even when corresponding column data were available. Additionally, CMs produced higher observed rate constants, exceeding those of BMs by a factor of $6.1 \pm 1.1$ standard error. In a subsequent laboratory investigation, 12 equivalent microcosm pairs were constructed from fractured bedrock and perchloroethylene (PCE) impacted groundwater. First-order PCE transformation kinetics of CMs were $8.0 \pm 4.8$ times faster than BMs (rates: $1.23 \pm 0.87$ vs. 0.16 $\pm 0.05 \mathrm{~d}^{-1}$, respectively). Additionally, CMs transformed 16.1 \pm 8.0-times more mass than BMs owing to continuous-feed operation. CMs are concluded to yield more reliable kinetic estimates because of much higher data density stemming from long-term, steady-state conditions. Since information from BMs and CMs is valuable and complementary, treatability studies should report kinetic data from both when available. This first systematic investigation of BMs and CMs highlights the need for a more unified framework for data use and reporting in treatability studies informing decision-making for field-scale groundwater remediation.
\end{abstract}




\section{Introduction}

Despite significant remediation efforts over the last few decades by the United States and other developed nations, the number of hazardous waste sites remains considerable. Assessments conducted by the United States Environmental Protection Agency (US EPA) concluded that 294,000 hazardous waste sites exist across the United States, with projected remediation costs amounting to more than $\$ 209$ billion [1]. With some of the easiest to remediate sites now closed, a large number of challenging sites remain, estimated to require greater than 100 years for cleanup, and containing recalcitrant or comingled contaminants, typically in hydrogeologically complex environments [2]. In the US, the largest category of recalcitrant contaminants is halogenated volatile organic compounds (VOCs). This contaminant class comprises the highest percentage of sites on the US EPA's National Priorities List (sites eligible for remedial action under the Comprehensive Environmental Response Compensation and Liability Act (CERCLA) or Superfund program), and the largest class of organic contaminants detected at Department of Defense installations [1]. Chlorinated solvents, which are the prime contributor to this category, are particularly challenging to remediate because of their pronounced recalcitrance to (bio)transformation and ability to form difficult to locate dense non-aqueous phase liquid (DNAPL) point sources [2].

The methodology for hazardous waste site characterization and remedial determination, known as Remediation Investigation/Feasibility Study (RI/FS), is outlined in CERCLA [3]. Integral to this framework is the use of treatability studies (often referred to as feasibility studies), intended to evaluate the performance, design and cost of potential remediation strategies before implementation [4]. Treatability studies require site geologic materials and groundwater to be tested with the proposed remedial technology, most commonly at the bench-scale. 
Although the US EPA offers treatability guidance documents designed to outline basic experimental parameters, a specific roadmap from inception to completion is not explicitly defined [5-7]. Thus the approach taken and data required to satisfy treatability study goals are open for interpretation.

Bench-scale treatability studies commonly use batch bottle or continuous-flow column designs to characterize and quantify contaminant changes in an experimental system as a proxy for in situ site conditions [8-10]. Batch microcosms (BMs), usually comprised of glass bottles with a narrow neck and orifice, are filled with geologic materials, site groundwater, amendments, and sealed with a gastight septum closure (closed systems). Batch bottle studies are the least expensive alternative in treatability studies and are the simplest to conduct [11-13]. Continuousflow column microcosms (CMs) are commonly fabricated from glass or plastic cylinders, with sampling ports located at the inlet and outlet, and sometimes along the length of the column [1416]. Columns are constructed with geologic material, solid amendments (optional), and groundwater is pumped through the column at a specified flow rate, typically in up-flow mode to remove trapped gases (open systems). Continuous-flow column experiments, although more expensive and challenging to operate, are known to be more representative of field conditions, by including the simulation of groundwater flow extant in the subsurface [17].

Data obtained from feasibility studies include the degree of removal (or sequestration) of the contaminant of interest, and are used to develop an understanding of the transformation kinetics [18-20]. In studies where the contaminant is chemically or biologically transformed, kinetic data are often presented in the form of rate constants, specifically as first-order rate constants $(k)$ and corresponding, concentration-independent half-lives ( $\left.\mathrm{t}_{1 / 2}\right)$ [21-23]. Often, these calculated parameters are directly compared to those of other studies with similar experimental designs, in 
an effort to further substantiate the feasibility of the tested technology [24-26]. First-order rate constants are often used to populate projection models, which are integral in determining the fate and transport characteristics of the contaminants of interest [27-30]. A kinetic analysis is arguably the most valuable calculated parameter because this approach supplies the time necessary for cleanup, which largely dictates overall remediation costs. However, the experimental design, type of data extracted, calculations completed, and the manner in which data are presented is not stipulated, thereby rendering it subject to considerations of time, money or other issues.

In this study, a meta-analysis of the scientific literature was performed to determine common approaches to the use and reporting of BM- and CM-derived kinetics. In addition, an experimental investigation was conducted to better understand fundamental differences in reaction kinetics derived from batch and column treatability studies. Experimental treatability studies were conducted using bedrock and groundwater impacted by perchloroethylene (PCE), one of the most frequently encountered recalcitrant groundwater contaminants in the US and around the world [31]. The fate of PCE in the environment is a function of prevailing physical, chemical and biological conditions at the cleanup site $[32,33]$, thus necessitating remedial design that is customized on a case-by-case basis informed by feasibility studies. Literature findings and original experimental data on combined batch and column BMs and CMs treatability studies were completed to elucidate the benefits and limitations of each.

\section{Materials and Methods}

\subsection{Literature Meta-analysis}


A literature review was conducted using Arizona State University’s OneSearch, which includes Web of Science, JSTOR, RefWorks and other sources (Table S1), to determine the number of combined batch and column chlorinated solvent treatability studies published in peerreviewed sources. Search criteria included an aggregate of the following keywords and phrases: batch, column, dechlorination, and 'rate constant.' Search results were refined by excluding the following subject terms: atmospheric protection/air quality control/air pollution, limnology, soil science and conservation, waste-water, wastewater treatment, sludge, water purification, and water purification methods. Publication dates included only those articles published from 2000 to 2014 . Of the total number of search results (sorted by relevance), $30 \%$ of the journal articles were selected randomly for evaluation. Studies captured in search results were excluded from analysis if they only employed analytical columns used in gas and liquid chromatography as opposed to microcosm columns (i.e., containing batch studies only).

\subsection{Experimental Investigation}

\subsubsection{Site Media}

Bedrock core and groundwater for microcosm experiments were collected from an industrial site in Ontario, Canada. Site groundwater was amended with PCE, trichloroethene (TCE) and cis-1,2-dichloroethene ( $c$ DCE) to concentrations of 57,43 and $31 \mathrm{mg} / \mathrm{L}$, respectively, for batch experiments and $57 \mathrm{mg} / \mathrm{L}$ PCE for columns. Concentrations of these PCE, TCE, and $c$ DCE at this particular site showed concentrations of $58 \pm 61 \mathrm{mg} / \mathrm{L}, 39 \pm 9 \mathrm{mg} / \mathrm{L}$, and $17 \pm 4 \mathrm{mg} / \mathrm{L}$, respectively, in the most heavily impacted areas. These are similar to concentrations found at other sites contaminated with chlorinated solvents [34-35].

\subsubsection{Microcosm Design}


Unless otherwise stated, microcosm treatment amendments were sourced from Golder Associates Ltd. (Ottawa, ON). Treatment 1 consisted of a proprietary Controlled-Release Carbon Source (CRCS A). Treatment 2 included a commercially available CRCS B/Microscale Zero Valent Iron (mZVI) blend known as EHC® (Peroxychem, Philadelphia, PA). Treatment 3 consisted of nanoscale ZVI (nZVI) with associated palladium acetate catalyst (TCI America, Boston, MA), and an organic carbon source (soy protein). Further details are included in Table S2.

Microcosms (Treatments 1-3) were bioaugmented with a commercial dechlorinating culture (KB-1 ${ }^{\circledR}$; SiREM, Guelph, ON) [36]. The chemical and biological treatments chosen are common amendments used for in situ groundwater remediation [36-38]. Control microcosms were created in duplicate, and experimental treatments in triplicate, with the exception of Treatment 1 columns (duplicate). CMs were attached to a multi-channel ISMATEC peristaltic pump (IDEX Health and Science, Oak Harbor, WA), and operated with upward flow at a rate of 0.25 pore volumes per day $(2.75 \mathrm{~mL} /$ day $)$, or a 4 -day residence time.

\subsubsection{Chemical Analysis}

Aqueous samples were collected on a weekly to biweekly basis for analysis of PCE, TCE, $c \mathrm{DCE}$, trans-1,2-dichloroethene (tDCE), 1,1-dichloroethene (1,1-DCE), vinyl chloride (VC) and ethene. Batch samples were analyzed using gas chromatography with a flame ionization detector (GC-FID) (Hewlett Packard 7890) (Hewlett Packard, Palo Alto, CA). Column samples were analyzed using headspace solid phase micro-extraction gas chromatography (SPME-GC-2010), with an FID and AOC-5000 auto-sampler (Shimadzu, Columbia, MD), using a previously published method [39]. Limits of detection and analyte recoveries are included in Table S3.

\subsubsection{Data Analysis}


Rate constants were calculated for BMs using the linear regression method $[12,40]$. Firstorder observed rate constants $\left(k_{\text {OBS }}\right)$ for columns were calculated for each sampling period using the following equation:

$-k_{O B S}=\frac{\ln \left(\frac{C}{c_{0}}\right)}{t}$

where, $C$ is effluent concentration, $C_{0}$ is influent concentration, and $t$ is time. The statistical relationship between batch and column rate constants were analyzed in unpaired, 2-tailed, homoscedastic Student's $t$-test.

The total contaminant mass converted to ethene $\left(M_{T o t}\right)$ in batch and continuous-flow microcosms were calculated using equation 2 .

$M_{T o t}=\left(\frac{C_{e t h}}{C_{e f f}}\right)\left(\frac{C_{i n^{*} t}}{\tau}\right)\left(V_{G W}\right)$

where, $C_{e t h}$ is total effluent molar concentration of ethene, $C_{e f f}$ is effluent molar concentration of total (chloro)ethenes, $C_{i n}$ is initial concentration of chloroethenes in batch or influent concentration in columns, $t$ is the study duration, $\tau$ is the residence time, and $V_{G W}$ is the groundwater volume in each microcosm. In columns, $V_{G W}$ may be further defined as the product of the column volume $\pi r^{2} h$ and porosity $\phi$, therefore equation 2 for continuous-flow columns may be written as follows:

$M_{T o t}=\left(\frac{C_{e t h}}{C_{e f f}}\right)\left(\frac{C_{i n^{*} t}}{\tau}\right)\left(\pi r^{2} h \phi \frac{t}{\tau}\right)$

In each equation, the first term is the ratio of ethene produced, the second is the maximum total ethene concentration possible in each microcosm from chloroethene conversion, and the final term is the volume of groundwater in or passing through the microcosm.

\section{Results and Discussion}




\subsection{Literature Meta-analysis}

A literature search using the criteria presented, yielded 644 publications. Analysis of $30 \%$ of these articles $(n=200)$ revealed that only $20 \%(n=40)$ (Table S4) included a combined study of treatability using both BMs and CMs; the remainder had erroneous hits for analytical rather than microcosm columns and dealt with batch studies only. Of the resultant combined batch and column studies, only $23 \%(n=9)$ performed a kinetic analysis using both datasets (Figure 1). Examination of these studies revealed that in 8 of the 9 studies (89\%), the observed rate constants in the columns were greater than those observed in batch systems. On average, column kinetics were greater by a factor of $6.1 \pm 1.1$ standard error than associated batch studies under similar experimental conditions.

The literature review revealed batch studies to be more common than column studies, with only a small fraction actually using both $\mathrm{BM}$ and $\mathrm{CM}$ approaches jointly. This is not surprising, as batch bottles are comparatively simpler systems with fewer moving parts that are easier to manage and replicate [17]. Notably, only $23 \%$ of studies with combined use of BMs and CMs conducted reported kinetic analysis results for both experimental approaches. In other words, in $77 \%$ of the studies, available data were not included in the final analysis and reporting. Results show an industry preference to rely on kinetic analyses from batch bottles even when complimentary continuous-flow column results are available. Additionally, only 1 of 9 papers reported both kinetic datasets and discussed the differences between the calculated rate constants. To better understand the benefits and limitations of the two approaches, we conducted an experimental comparison of both systems under standardized conditions.

\subsection{Experimental Application}


Paired, matching $\mathrm{BM}$ and $\mathrm{CM}$ studies were conducted with equivalent experimental conditions for a duration of 146 days (Figure 2), and resultant (chloro)ethene species and associated first-order rate constants determined.

\subsubsection{VOC Speciation During Batch and Column Incubation}

Results from the biotic control and bioaugmentation treatments in BMs and CMs spanned the PCE degradation spectrum from negligible to complete dechlorination, similar to chloroethene treatability studies reported in the literature for laboratory and field investigations [50-52]. Here, chloroethene mole fractions obtained in batch systems showed higher percentages of lighter molecular-weight PCE transformation products compared to the respective column series (Figure 3). This pattern relates to differences in chloroethene compound additions and the residence time in each treatability system. In batch, there is a finite input of contaminant into the system at the start of the study, and a residence time equivalent to the study duration ( $\sim 150$ days). In the column system chloroethenes are continuously being introduced, with a residence time of only 4 days. The primary chloroethene(s) at study conclusion for BMs with Treatment 1 were $75 \%$ VC (PCE removed by Day 34), as compared to 45/40\% TCE/PCE in the corresponding CMs. In Treatment 2, BMs and CMs displayed ethene production at 70\% and $45 \%$, respectively; however, PCE was removed by Day 41 in BMs, while $6 \%$ remained in column effluent at the study conclusion on Day 146. In Treatment 3, both microcosm pairs showed $\sim 100 \%$ ethene production (PCE removed approximately by Day 75). These findings from equivalent microcosms confirmed data from the literature, indicating a similar pattern of higher production of PCE/TCE degradation products (e.g., $c$ DCE, VC and ethene) in batch over column microcosms $[43,49]$.

\subsubsection{Transformation Kinetics of Batch and Column Microcosms}


Results within analogous experimental series showed CMs to have higher observed rate constants (i.e., faster reaction rates) than BMs for identical dechlorination patterns (Figure 4). First-order rate constants of PCE transformation (removal) in columns were $8.0 \pm 4.8$ times faster than those of batch bottles, $1.23 \pm 0.87$ vs. $0.16 \pm 0.05 \mathrm{~d}^{-1}$, respectively. On average, CMs in Treatment 1,2 and 3 were $3.1 \pm 1.9\left(0.5\right.$ vs. $\left.0.2 \mathrm{~d}^{-1}\right), 8.1 \pm 4.1\left(0.9\right.$ vs. $\left.0.1 \mathrm{~d}^{-1}\right)$ and $11.8 \pm 1.8$ (2.1 vs. $0.2 \mathrm{~d}^{-1}$ ) times faster than associated BMs, respectively. This relationship was statistically significant for each treatment: Treatment $1(p<0.05)$, Treatments 2 and $3(p<0.001)$.

Box and whisker plots served to inform a detailed, VOC species-resolved comparison of BMs and CMs, showing the $25^{\text {th }}, 50^{\text {th }}$ (median), and $75^{\text {th }}$ quartiles with whiskers $1.5 \mathrm{x}$ the interquartile (IQR) range (Figure 4). Rate constant variation within column data was greater, as evidenced by the larger quartiles, standard deviations, and the presence of both minimum and maximum outliers. These differences in data variability are explained by the following columns properties: $(i)$ greater number of data points; (ii) multiple rates per replicate (during steady-state formation); (iii) influent samples collected for each sample event, and (iv) first-order integrated rate law containing two variables (influent and effluent). These cited differences are a function of the rate calculation method used: linear regression method (batch) versus application of firstorder integrated rate law (columns), which stems from inherent differences in physical structure and functionality.

\subsubsection{Contaminant Mass Converted in Batch and Column Microcosms}

A direct comparison of the two experimental approaches revealed that the total mass of contaminant removed from BMs and CMs is not only dependent on the effective transformation activity, but also on the mass delivered to the system over the study duration. With a residence time equivalent to the experimental duration (here 146 days), each BM received a total VOC 
mass of $28 \mathrm{mg}$, or $11.4 \mathrm{mg}$ PCE, $8.6 \mathrm{mg}$ TCE and $6.2 \mathrm{mg} c \mathrm{DCE}$ (of $0.07 ; 0.07$; and 0.06 millimoles (mmol), respectively). Total contaminant removals in batch Treatments 1 through 3 (determined by percent ethene production) were $6.0 \pm 1.3 \mathrm{mg}(0.21 \pm 0.05 \mathrm{mmol}), 23.6 \pm 6.9 \mathrm{mg}$ $(0.84 \pm 0.25 \mathrm{mmol})$, and $27.7 \pm 0.05 \mathrm{mg}(0.99 \pm 0.002 \mathrm{mmol})$. The average removal across all treatments for batch bottles was $19 \pm 10 \mathrm{mg}(0.68 \pm 0.36 \mathrm{mmol})$.

By comparison, CMs showed an average treatment removal of $314 \pm 271 \mathrm{mg}(11.2 \pm 9.7$ mmol) as ethene, a 16-fold increase in total contaminant conversion over the associated batch equivalents $(19 \pm 10 \mathrm{mg})$. Individually, column Treatments 1,2 and 3 had total contaminant removals of $0 \mathrm{mg}$ (no ethene production), $204 \pm 100 \mathrm{mg}(7.3 \pm 3.6 \mathrm{mmol})$, and $632 \pm 85 \mathrm{mg}$ ( $22.5 \pm 3.0 \mathrm{mmol})$, respectively. This increased removal in columns is largely driven by the 4 day residence time. The maximum contaminant mass for the batch systems is the mass supplied at the outset of the experiment, whereas in the column system, the total mass is the mass delivered per pore volume multiplied by the number of pore volumes processed during the study duration. Hence, CMs over time receive a higher overall mass of VOCs and therefore also can transform a comparatively larger mass over time. In this study, the maximum VOC removal per CMs was $656 \mathrm{mg}(23.4 \mathrm{mmol})$, or 23-times higher than that of its $\mathrm{BM}$ analog producing the same experimental outcome (rate) but transforming only a total of $28 \mathrm{mg}(1.0 \mathrm{mmol})$.

\subsubsection{Comparison of Laboratory and Meta-analysis Data}

The experimental data collected here on differences in average and maximum rate constants of PCE transformation (7.7 and 10.6, respectively) fell soundly within the range of values established in the literature meta-analysis (Figure 1). Discerning the inherent variability between batch and column experiments within the literature cited in the meta-analysis is challenging. Reasons for this include: (i) one or both microcosm types did not have a replicate [46]; (ii) 
replicates are not truly replicates with variation in an additional parameter (e.g., dissolved oxygen, temperature) $[45,47,48]$; (iii) replicate results are not presented $[42,43]$; (iv) replicate results are presented in multiple graphs (instead of a single graph with error bars) [41, 43, 44, 49]; (v) replicate results are plotted together without discerning which replicate is which [49]. However in two studies, greater variability in columns data over batch data can qualitatively be discerned [41, 49], which agrees with the experimental results.

In the literature cited in the meta-analysis, the total mass of contaminant removed over the study duration was not included, however relevant metrics, when available, were extracted to estimate the total contaminant mass introduced into or pumped through the two microcosm systems. This number is not indicative of mass removed, but provides a theoretical maximum assuming complete conversion by the selected treatment. In each instance where estimations were possible, results showed that CMs processed greater total contaminant masses than the associated BMs, agreeing with the results of the present study [41, 43, 44, 49]. A 2011 study showed masses of $11 \mathrm{mg}$ for batch systems and approximately 600 to $2300 \mathrm{mg}$ for the columns (range a function of flow rate variation) [43]. A 2007 study had calculated masses of 2 to $12 \mathrm{mg}$ for batch as compared to approximately 300 to $3000 \mathrm{mg}$ for columns [41]. Similarly, a 2009 study had calculated masses for batch and columns of $0.2 \mathrm{mg}$ and $75 \mathrm{mg}$, respectively. Differences in total contaminant mass in the cited treatability studies ranged between 10 - and 106-fold. The present study is on the lower range of this spectrum because of the comparatively low flow rates [44].

\subsubsection{Informational Value of Batch and Column Microcosms}

The number of data points $(n)$ used in kinetic calculations for microcosms varied from 6 to 36 for columns to from 2 to 3 for batch bottles (Figure 4). Data density for BMs were 
considerably lower than for columns because of inherent design differences, where the number of rate constants is equivalent to the number of bottle replicates in the series. This method of batch rate calculation is common and few rate constants are generated, typically, one rate per bottle [53-55]. In CMs, each discrete sampling point produced a unique rate, calculated based on the delta between influent and effluent concentration; therefore $n$ was determined by the number of sampling points occurring after steady-state was achieved. The higher number of data points generated in columns creates what amounts to more reliable estimates for maximum and sustained rates thus may be considered a better predictor of long-term in situ kinetic activity.

\subsection{Conceptual Comparison of Batch and Column Microcosms}

Batch bottles and continuous-flow columns are inherently different by design and consequently produce not only dynamically different system conditions but also variant kinetic results, as shown in this study and in the literature. In BMs, the system is static (no flow), as compared to the flow-through design of CMs; this difference is often cited as the reason for differences between the two microcosms [56]. We conclude that in addition to differences in flow regime, the closed system/finite contaminant input of the batch bottle versus the open system/continuous contaminant input, drives the variability. Open and closed system designs produce different oxidation-reduction potentials [44, 57], particularly a highly reduced system (over time) in BMs as the finite mass of electron acceptors $\left(\mathrm{O}_{2}, \mathrm{NO}_{2}^{-}\right.$, VOCs) are consumed in sequential, hierarchical fashion. This is juxtaposed to the variable reducing conditions in columns (temporally and spatially), which depend on influent storage and flow rate (Figure 5). With the closed system of BMs, the residence time is synonymous with study duration, therefore with analogous amendment concentrations and dechlorination ability, columns passing multiple pore volumes will by default encounter and remove more contaminant mass. 
Batch and column microcosms show variation in the ability to illustrate the phases of contaminant removal including: lag, acceleration, steady-state and decline (Figure 5). In both microcosm types, the occurrence of a lag phase is visible. In BMs, the lag phase presents as persistent (near)-initial contaminant concentrations after study inception, and in CMs it is displayed as near-identical influent and effluent concentrations. Discerning the acceleration and steady-state phases in BMs is challenging. Typically, the decline in amendment concentrations as a whole is considered the acceleration phase $[58,59]$. Since the ratio of parent to product compounds is constantly changing in this type of system [60, 61], steady-state can never be attained. In contrast, the acceleration phase in CMs typically shows notable variability in effluent concentrations between adjacent sampling events. As steady-state conditions are achieved, there is a high reproducibility in the delta of influent and effluent concentrations during adjacent sampling periods, which can be observed for extended periods of weeks or months. It is important to note that performing batch microcosm experiments with repeated influent injections in a semi-continuous fashion can create steady-state conditions [62], however, this study was interested in the strict closed system design. The final phase, decline (end of amendment lifetime) cannot usually be separated from an initial degradation sequence in BMs and requires subsequent chemical contaminant additions to the system. In CMs however, end of performance is signaled as a reappearance (break-through) of the contaminant of interest fed in column effluent.

\subsection{Determination of Amendment Dosages and Durability}

The literature review showed that electron donor dosages for field studies are often selected based on results from batch bottle studies. This may be problematic, however, when considering the addition of controlled-release carbon sources (CRCS). In BMs, the concentration of electron 
donors from CRCS is a function of the release rate and the length of the lag phase, with the latter allowing for a potential accumulation of donors. In CMs in which the CRCS are packed into the column (as done in this study), electron donor concentrations are expected to be less variable, as they cannot accumulate due to the continuous flushing of the column (Figure 5). With this experimental design, the practitioner can observe the transformation activity resulting from the processing of larger volumes of fluid, which is expected to be more similar to conditions prevailing at the field-scale during CRCS subsurface injections. Consequently, the effectiveness and durability of slow-release compounds may be best assessed through the use of continuousflow columns. The differences observed in dechlorination activity between BMs and CMs in the Treatment 1 series (and in a limited fashion in Treatment 2) may have been related to the above phenomenon. Due to the delay of inoculation with the bioaugmentation agent by one month (necessitated by the requirement of the bioaugmentation agent for strictly anaerobic conditions), it is reasonable to expect that the available concentration of electron donors derived from the CRCSs was higher in batch bottles than in continuous-flow systems.

\subsection{Understanding Data Inconsistencies Between Batch and Column Microcosms}

The overall faster rates observed in CMs relative to equivalent BMs are not surprising. From a microbiological standpoint, continuous-flow systems typically yield better overall performance because they result in adaptation and attainment of steady-state conditions that favor mass removal $[43,63]$. Moreover, flow through the column does not allow for the accumulation of waste products of microbial metabolism, which could decrease biodegradation performance. Additionally, a spectrum of redox conditions can be established in columns, with different types of microbes co-existing and co-transforming contaminants at the same time but in different physical locations along the length of the column. Therefore, columns harbor a spatially 
expansive diversity of microbial consortia, all potentially contributing to successful contaminant removal $[52,64]$. In batch bottles, the same reactions occur, but they are temporally constrained rather than spatially contiguous [65].

\subsection{Study Limitations}

For reasons of practicality, only $30 \%$ of the total number of published articles captured by search engine criteria were examined in detail; therefore, the ratio of batch to column degradation rates derived here may differ slightly from the comprehensive, true value representing all studies. However, the data are normally distributed which suggests that extracted values from captured results constitute a representative sample of the entirety of data (Figure S1). The selected field location was a fractured bedrock site and constructing representative microcosms from such materials presents a challenge. Here, we adopted use of crushed bedrock cores, leaving open the possibility of creating reactive surfaces not representative of weathered rock in place in situ. However, the goal of the work was to compare rates from batch bottle and column microcosms, and since both were constructed with the same material no adverse impact from this experimental design is expected. In laboratory experiments, as is typical for long-term operation of column studies, prolonged storage of groundwater was necessary. Error was decreased by bimonthly preparation of PCE-amended influent to achieve the desired VOC concentration.

Authors focused on a comparison of observed rate constants in this study; alternative approaches can be envisioned, such as normalizing transformation activity by parameters of known importance, e.g., surface area and or biomass. Both approaches potentially can be of value but also are flawed by the fact that neither parameter can be determined with great certainty for in situ settings in the field, to which the rates ultimately are applied. 


\subsection{Applicability of Study Results}

Whereas many of the aspects discussed above and captured in Table 1 should be broadly applicable for feasibility determinations, care must be taken when extrapolating the results of this work to other situations, such as different redox conditions (e.g., aerobic conditions) and other contaminants. For VOC removal under anoxic conditions, we established that BMs tend to produce a higher percentage of lighter molecular weight PCE byproducts relative to CMs, and that columns tend to show faster kinetics than batch. Thus, if only batch bottle kinetics are available, conservative rate estimates result that may be lower than actually attainable rates. Total mass removal in columns is greater than in batch systems under equivalent starting conditions, because in columns, the contaminants are constantly replenished by influent flow. Since CMs can attain and maintain steady-state conditions, they yield a higher number of data points than BMs, which should apply broadly beyond VOC scenarios investigated here. The conclusion concerning the better utility of columns for determining the dosage and durability of slow-release compounds also is expected to extend to other electron donors formulations and contaminant scenarios. In studies examining the impact of highly reducing redox conditions, batch bottles are the methodology of choice because maintaining such conditions in flow-through columns is challenging.

\subsection{Conclusions}

Given the differences between batch bottle and continuous-flow column studies established herein and summarized above, it is desirable to establish guidelines for treatability studies. It is imperative to evaluate the behavior of both open and closed system treatability studies to understand how the inherent characteristics of each system may affect the overall capability of the amendment to effect remediation in the subsurface. This appears to be particularly important 
for controlled-release carbon sources. Here, disparate patterns of activity are expected and were indeed observed in batch and column studies (poorer initial performance in columns). In this situation, reliance on batch data alone may result in an overestimation of in situ dechlorination activity, as electron donors are allowed to accumulate over time in bottles, a scenario that does not accurately mimic flow-through, real-world conditions. Batch systems are best for determining chemical species arising during remediation and for determining possible endpoints of treatment. Flow-through systems are generally better suited to inform on reaction kinetics and can reveal mass transfer limitations that are masked in batch bottles due to long incubation times and mixing, or a combination of the two. A helpful parameter to consider when interpreting microcosm experiments is the total mass removed over the study duration, with column experiments featuring higher total masses than batch systems due to continuous introduction of contaminants. Column studies favor a proper estimation of the expected lifetime and effectiveness of amendments during field-scale applications. Thus, the combined use of batch and column feasibility studies may reduce the risk of remediation failure at the field scale and will help to minimize costs to achieve remediation in a timely manner. While much can be learned from feasibility studies, monitoring at the field scale remains essential, as even the best microcosm design cannot fully capture the conditions and heterogeneity that are inherent to subsurface cleanup sites. 


\section{Acknowledgments}

We thank Dr. Rosa Krajmalnik-Brown, Isaac Roll, and Arjun Venkatesan for providing feedback on early drafts of this manuscript. This work was partially funded by Award Number ER200914 from the Environmental Security Technology Certification Program of the Department of Defense (DoD), and Award Numbers R01ES015445 and 1R01ES020889 from the National Institute of Environmental Health Sciences (NIEHS). The content is solely the responsibility of the authors and does not necessarily represent the official of funding agencies. 


\section{References}

[1] Cleaning up the Nation's Waste Sites: Markets and Technology Trends; Highlights of EPA/542/R-04/015; United States Environmental Protection Agency: Washington, D.C., 2004; https://clu-in.org/download/market/2004market.pdf.

[2] Alternatives for Managing the Nation's Complex Contaminated Groundwater Sites; National Resource Council: The National Academies Press: Washington, D.C., 2013.

[3] Remedial Investigation/Feasibility Study. United States Environmental Protection Agency. http://www.epa.gov/superfund/superfund-remedial-investigationfeasibility-study-sitecharacterization.

[4] Guide for conducting treatability studies under CERCLA: Final; Highlights of EPA/540/R92/071a; United States Environmental Protection Agency: Washington, D.C., 1992; http://nepis.epa.gov/Exe/ZyPURL.cgi?Dockey=100020Z1.txt.

[5] J.M. Rawe, S. Krietemeyer, E. Meagher-Hartzell, Guide for conducting treatability studies under CERCLA: biodegradation remedy selection: interim guidance; Highlights of EPA/540/R-93/519a; United States Environmental Protection Agency: Washington, D.C., 1993; http://nepis.epa.gov/Exe/ZyPURL.cgi?Dockey=1000228N.txt.

[6] G.D. McNelly, Guide for conducting treatability studies under CERCLA: chemical dehalogenation; Highlights of EPA/540/R-92/013a; United States Environmental Protection Agency: Cincinnati, OH, 1992; http://nepis.epa.gov/Exe/ZyPURL.cgi?Dockey=100020WX.txt

[7] Guide for conducting treatability studies under CERCLA: aerobic biodegradation remedy screening: interim guidance; Highlights of EPA/540/R-91/013a; United States 
Environmental Protection Agency: Cincinnati, OH, 1991;

http://nepis.epa.gov/Exe/ZyPURL.cgi?Dockey=10001JR6.txt

[8] S. Lee, L. Lalhmunsiama, D. Tiwari, Sericite in the Remediation of Cd(II)- and Mn(II)contaminated Waters: Batch and Column Studies, Environ. Sci. Pollut. Res. 21 (2014) 3686-3696.

[9] M.R. Olson, J. Blotevogel, T. Borch, M.A. Petersen, R.A. Royer, T.C. Sale, Long-term potential of in situ chemical reduction for treatment of polychlorinated biphenyls in soils, Chemosphere 114 (2014) 144-149.

[10] X. Hu, Z. Ding, A.R. Zimmerman, S. Wang, B. Gao, Batch and column sorption of arsenic onto iron-impregnated biochar synthesized through hydrolysis, Water Res. 68 (2015) 206216.

[11] L.J. Matheson, P.G. Tratnyek, Reductive dehalogenation of chlorinated methanes by iron metal, Environ. Sci. Technol. 28 (1994) 2045-2053.

[12] H. Song, E.R. Carraway, Reduction of Chlorinated Ethanes by Nanosized Zero-Valent Iron: Kinetics, Pathways, and Effects of Reaction Conditions, Environ. Sci. Technol. 39 (2005) 6237-6245.

[13] M.B. Lindsay, C.J. Ptacek, D.W. Blowes, W.D. Gould, Zero-valent iron and organic carbon mixtures for remediation of acid mine drainage: Batch experiments, Appl. Geochem. 23 (2008) 2214-2225.

[14] S.W. Orth, R.W. Gillman, Dechlorination of Trichloroethene in Aqueous Solutions Using $\mathrm{Fe}^{0}$, Environ. Sci. Technol. 30 (1996) 66-71.

[15] J. Klausen, R.J. Vikesland, T. Kohn, D.R. Burris, W.P. Ball, A.L. Roberts, Longevity of Granular Iron in Groundwater Treatment Processes: Solution Composition Effects on 
Reduction of Organohalides and Nitroaromatic Compounds, Environ. Sci. Technol. 37 (2003) 1208-1218.

[16] B. Baumgarten, J. Jahrig, T. Reemstsma, M. Jekel, Long term laboratory column experiments to simulate bank filtration: Factors controlling removal of sulfamethoxazole, Water Res. 45 (2011) 211-220.

[17] J. Conca, E. Strietelmeier, N. Lu, S.D. Ware, T.P. Taylor, J. Kaszuba, J. Wright, Treatability Study of Reactive Materials to Remediate Ground Water Contaminated with Radionuclides, Metals and Nitrates in a Four-Component Permeable Reactive Barrier. In Groundwater Remediation of Trace Metals, Radionuclides, and Nutrients, with Permeable Reactive Barriers; D.L. Naftz, S.J. Morrison, J.A. Davis, C.C. Fuller, Academic Press: California (2002) 221-252.

[18] SiREM laboratory website. http://www.siremlab.com/services/treatability-testing

[19] S. Jeen, S. Lazar, L. Gui, R.W. Gillham, Degradation of chlorofluorocarbons using granular iron and bimetallic irons, J. Contam. Hydrol. 158 (2014) 55-64.

[20] Y. Mamindy-Pajany, S. Sayen, E. Guillon, Impact of lime-stabilized biosolid application on $\mathrm{Cu}, \mathrm{Ni}, \mathrm{Pb}$ and $\mathrm{Zn}$ mobility in an acidic soil, Environ. Sci. Pollut. R. 21 (2014) 44734481.

[21] H. Liu, Q. Wang, C. Wang, X.Z. Li, Electron efficiency of zero-valent iron for groundwater remediation and wastewater treatment, Chem. Eng. J. 215-216 (2013) 90-95.

[22] S.D. Justicia-Leon, S. Higgins, E.E. Mack, D.R. Griffiths, S.Q. Tang, E.A. Edwards, F.E. Loffler, Bioaugmentation with Distinct Dehalobacter Strains Achieves Chloroform Detoxification in Microcosms, Environ. Sci. Technol. 48 (2014) 1851-1858. 
[23] F. Suja, F. Rahim, M.R. Taha, N. Hambali, M.R. Razali, A. Khalid, A. Hamzah, Effects of local microbial bioaugmentation and biostimulation on the bioremediation of total petroleum hydrocarbons (TPH) in crude oil contaminated soil based on laboratory and field observations. Int. Biodeter. Biodegr. 90 (2014) 115-122.

[24] P. Kumar, M. Nemati, G.A. Hill, Biodegradation kinetics of 1,4-benzoquinone in batch and continuous systems, Biodegradation 22 (2011) 1087-1093.

[25] M.G. Mahmoodlua, S.M. Hassanizadeha, N. Hartoga, Evaluation of the kinetic oxidation of aqueous volatile organic compounds by permanganate, Sci. Total Environ. 485-486 (2014) $755-763$.

[26] Z. Li, Y. Inoue, S. Yang, N. Yoshida, A. Katayama, Mass balance and kinetic analysis of anaerobic microbial dechlorination of pentachlorophenol in a continuous flow column. J. Biosci. Bioengin. 110 (2010) 326-332.

[27] R.A. Brennen, R.A. Sanford, C.J. Werth, Biodegradation of Tetrachloroethene by Chitin Fermentation Products in a Continuous Flow Column System, J. Environ. Eng. 132 (2006) 664-673.

[28] C. Kantar, C. Ari, S. Keskin, Z.G. Dogaroglu, A. Karadeniz, A. Alten, Cr(VI) removal from aqueous systems using pyrite as the reducing agent: Batch, spectroscopic and column experiments, J. Contam. Hydrol. 174 (2015) 28-38.

[29] S. Bilardi, R.T. Amos, D.W. Blowes, P.S. Calabro, Moraci, N. Reactive Transport Modeling of ZVI Column Experiments for Nickel Remediation, Ground. Monitor. Rem. 33 (2013) 97-104. 
[30] G.V. Lowry, M. Reinhard, Pd-Catalyzed TCE Dechlorination in Water: Effect of $\left[\mathrm{H}_{2}\right](\mathrm{aq})$ and $\mathrm{H}_{2}$-Utilizing Competitive Solutes on the TCE Dechlorination Rate and Product Distribution, Environ. Sci. Technol. 35 (2001) 696-702.

[31] Superfund NPL Characterization Project: National Results; Highlights of EPA/540/891/069; United States Environmental Protection Agency: Washington, DC, 1991; http://nepis.epa.gov/Exe/ZyPURL.cgi?Dockey=20012FTM.txt

[32] D.M. Mackay, P.V. Roberts, J.A. Cherry, Transport of organic contaminants in groundwater, Environ. Sci. Technol. 19 (1985) 384-392.

[33] C.S. Carr, J.B. Hughes, Enrichment of High-Rate PCE Dechlorination and Comparative Study of Lactate Methanol, and Hydrogen as Electron Donors to Sustain Activity, Environ. Sci. Technol. 32 (1998) 1817-1824.

[34] Interstate Technology and Regulatory Cooperation (ITRC) Working Group, Dense Nonaqueous Phase Liquids (DNAPLs): Review of Emerging Characterization and Remediation Technologies ITRC, 2000.

[35] G. Davis, B.R. Baldwin, A.D. Peacock, D. Ogles, G.M. White, S.L. Boyle, E. Raes, S.S. Koenigsberg, K.L. Sublette, Integrated approach to PCE-impacted site characterization, site management, and enhanced bioremediation, Remed. J. 18 (2008) 5-17.

[36] D.W. Major, M.L. McMaster, E.E. Cox, E.A. Edwards, S.M Dworatzek, E.R. Hendrickson, M.G. Starr, J. Payne, L.W. Buonamici, Field Demonstration of Successful Bioaugmentation to Achieve Dechlorination of Tetrachloroethene to Ethene, Environ. Sci. Technol. 36 (2002) 5106-5116. 
[37] J.G. Arnason, M. Harkness, B. Butler-Veytia, Evaluating the Subsurface Distribution of Zero-Valent Iron Using Magnetic Susceptibility, Ground Water Mont. R. 34 (2014) 96106.

[38] W. Zhang, Soy proteins and/or soy derivatives with zero-valent iron compositions and use for environmental remediation. U.S. Patent 11/843,970, February 28, 2008.

[39] M. Ziv-El, T. Kalinowski, R. Krajmalnik-Brown, R.U. Halden, Simultaneous Determination of Chlorinated Ethenes and Ethene in Groundwater Using Headspace SolidPhase Microextraction with Gas Chromotography, J. Chromatogr. Sci. 52 (2013) 137-142.

[40] G.D. Wardlaw, R.K. Nelson, C.M. Reddy, D.L. Valentine, Biodegradation preference for isomers of alkylated naphthalenes and benzothiophenes in marine sediment contaminated with crude oil, Org. Geochem. 42 (2011) 630-639.

[41] J.H. Choi, Y.H. Kim, S.J. Choi, Reductive dechlorination and biodegradation of 2,4,6trichlorophenol using sequential permeable reactive barriers: Laboratory studies, Chemosphere 67 (2007) 1151-1557.

[42] E.I. Garcia-Pena, P. Zarate-Sequra, P. Guerra-Blanco, T. Poznyak, I. Chairez, Enhanced Phenol and Chlorinated Phenols Removal by Combining Ozonation and Biodegradation, Water Air Soil Poll. 223 (2012) 2047-4064.

[43] P.J. Haest, J. Philips, D. Springael, E. Smolders, The reactive transport of trichloroethene is influences by residence time and microbial numbers, J. Contam. Hydrol. 119 (2011) 89-98.

[44] Y.P. Katsenovich, F.R. Miralles-Wilhelm, Evaluation of nanoscale zerovalent iron particles for trichloroethene degradation in clayey soils, Sci. Total Environ. 407 (2009) 4986-4993.

[45] T. Lee, C.H. Benson, G.R. Eykholt, Waste green sands as reactive media for groundwater contaminated with trichloroethylene (TCE), J. Hazard. Mater. 109 (2004) 25-36. 
[46] Z. Li, Y. Inoue, S. Yang, N. Yoshida, A. Katayama, Mass balance and kinetic analysis of anaerobic microbial dechlorination of pentachlorophenol in a continuous flow column, J. Biosci. Bioeng. 110 (2010) 326-332.

[47] K. Mackenzie, J. Battke, R. Koehler, F.D. Kopinke, Catalytic effects of activated carbon on hydrolysis reactions of chlorinated compounds Part 2. 1,1,2,2,-Tetrachloroethane, Appl.

Catal. B. 59 (2005) 171-179.

[48] T.T. Tsai, C.M. Kao, T.Y. Yeh, S.H. Liang, H.Y. Chien, Application of surfactant enhanced permanganate oxidation and biodegradation of trichloroethylene in groundwater, J. Hazard. Mater. 161 (2009) 111-119.

[49] C.E. Schaefer, C.W. Condee, S. Vainbery, R.J. Steffan, Bioaugmentation for chlorinated ethenes using Dehalococcoides sp.: Comparison between batch and column experiments, Chemosphere 75 (2009) 141-148.

[50] S. Yu, L. Semprini, Kinetics and Modeling of Reductive Dechlorination at High PCE and TCE Concentrations, Biotechnol. Bioeng. 88 (2004) 451-464.

[51] C.M. Kao, S.C. Chen, J.Y. Wang, Y.L. Chen, S.Z. Lee, Remediation of PCE-contaminated aquifer by an in situ two layer Biobarrier: laboratory batch and column studies, Water Res. 37 (2003) 27-38.

[52] M.F. Azizian, S. Behrens, A. Sabalowsky, M.E. Dolan, A.M. Spormann, L. Semprini, Continuous-flow column study of reductive dehalogenation of PCE upon bioaugmentation with Evanite enrichment culture, J. Contam. Hydrol. 100 (2008) 11-21.

[53] Y. Kim, D.J. Arp, L. Semprini, Kinetic and Inhibition Studies for the Aerobic Cometabolism of 1,1,1-Trichloroethane, 1,1-Dichloroethylene, and 1,1-Dichloroethane by a Butane-Grown Mixed Culture, Biotechnol. Bioeng. 80 (2002) 498-508. 
[54] J. Dries, L. Bastiaens, D. Springael, S. Kuypers, S.N. Agathos, L. Diels, Effect of humic acids on heavy metal removal by zero-valent iron in batch and continuous flow column systems, Water Res. 39 (2005) 3531-3540.

[55] M.N. Kathiravan, R. Karthick, K. Muthukumar, Ex Situ bioremediation of Cr(VI) contaminated soil by Bacillus sp.: Batch and continuous studies, Chem. Eng. J. 169 (2011) $107-115$.

[56] Permeable Reactive Barrier Technologies for Contaminant Remediation; EPA/600/R98/125; United States Environmental Protection Agency: Washington, D.C., 1998; http://nepis.epa.gov/Exe/ZyPURL.cgi?Dockey=30003OIO.txt.

[57] K. McClellan, A New Approach to Groundwater Remediation Treatability Studies Moving Flow-through Column Experiments from Laboratory to In Situ Operation. Ph.D. Dissertation, Arizona State University, Tempe, AZ, (2013).

[58] K. Chandran, B.F. Smets, Biokinetic characterization of the acceleration phase in autotrophic ammonia oxidation, Water Environ Res. 80 (2008) 732-739.

[59] M.P. Shah, Microbial Removal of Ammonical Nitrogen by Nitrification and Denitrification, J. Bioremed. Biodeg. 9 (2015) 1-10.

[60] A.J. Saldanha, M.J. Brauer, D. Botstein, Nutritional Homeostasis in Batch and Steady-State Culture of Yeast, Mol. Biol. Cell. 15 (2004) 4089-4104.

[61] D.P. Searson, S.C. Burnham, M.J. Willis, A.R. Wright, Identification of chemical reaction mechanisms from batch process data, Proceedings of the $17^{\text {th }}$ IASTED International Conference on Modeling and Simulation, (2006) 511-516. 
[62] U. Jenal-Wanner, P.L. McCarty, Development and Evaluation of Semicontinuous Slurry Microcosms to Simulate in Situ Biodegradation of Trichloroethylene in Contaminated Aquifers, Environ. Sci. Technol. 31 (1997) 2915-2922.

[63] K. Choi, W. Lee, Reductive dechlorination of carbon tetrachloride in acidic soil manipulated with iron(II) and bisulfide ion, J. Hazard. Mater. 172 (2009) 623-630.

[64] T. Kalinowski, Technical, Economical and Social Aspects of Moving Treatability Studies for In Situ Bioremediation of Contaminated Aquifers from the Laboratory to the Field, Ph.D. Dissertation, Arizona State University, Tempe, AZ, (2013).

[65] W.R. Kelly, G.M. Hornberger, J.S. Herman, A.L. Mills, Kinetics of BTX biodegradation and mineralization in batch and columns systems, J. Contam. Hydrol. 23 (1996) 113-132. 


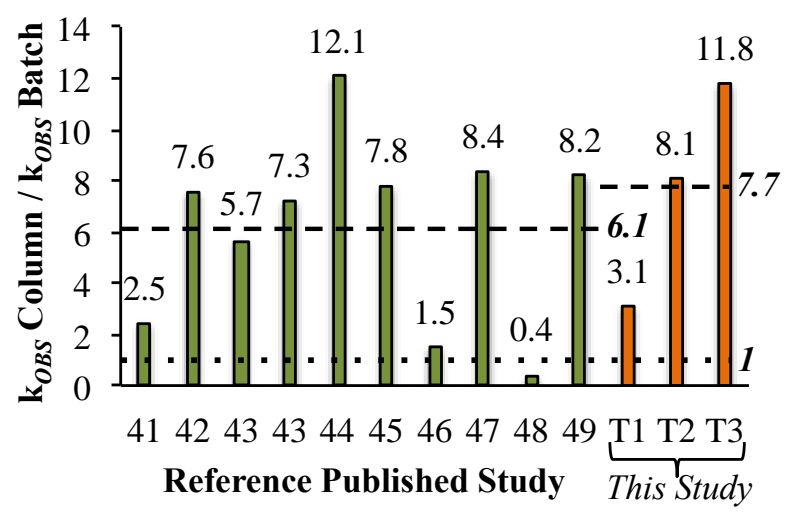

Fig. 1. Ratio of continuous-flow column to batch bottle rate constants $\left(k_{O B S}\right)$ from studies using both types of treatability study approaches. A ratio of unity (1) signals equivalent rates. In 8 of 9 referenced studies $(89 \%)$, ratios were higher that 1 , and published studies averaged a factor of $6.1 \pm 1.1$ standard error, indicating that columns consistently produced higher rate constants than comparable batch bottles [41-49]. Experimental results show Treatments (T) were within the published range with an average of $7.7 \pm 4.4$. 


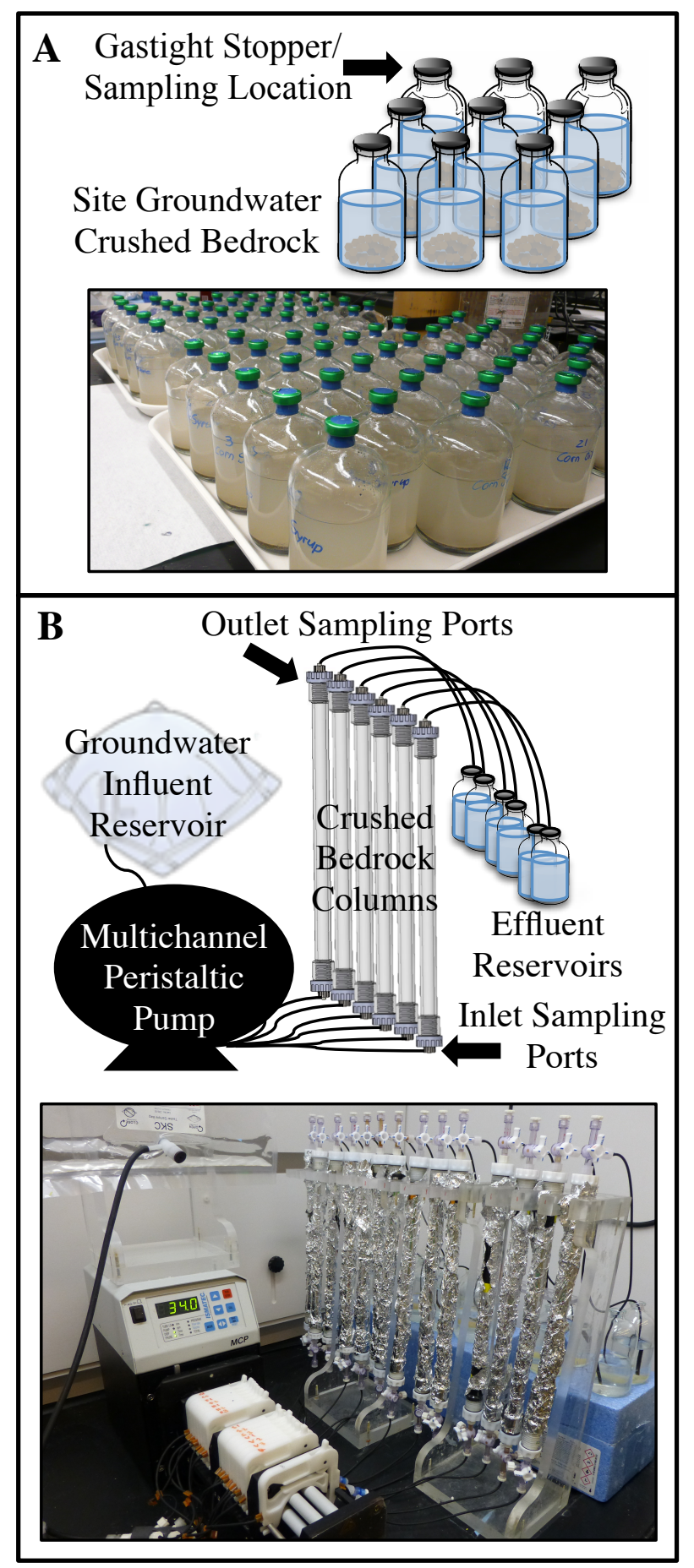

Fig. 2. Schematics and photographs of the experimental setup of batch bottle microcosms (A) and continuous-flow column microcosms (B). 


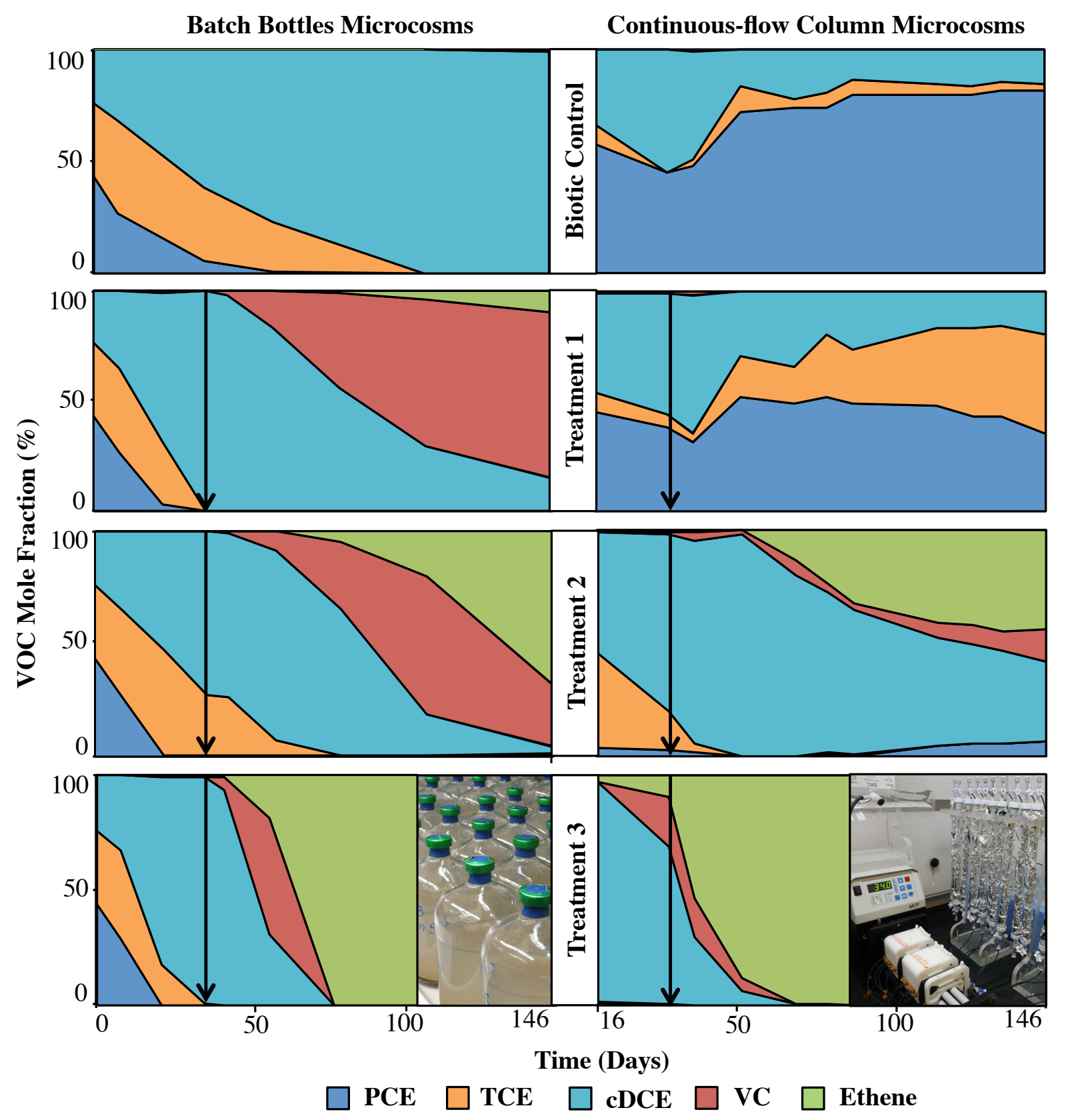

Fig. 3. Dechlorination results in Control and Treatment microcosms operated in batch and continuous-flow mode. Results are shown as percent VOC mole fraction throughout the study period. Arrows indicate inoculation of microcosms with a dechlorinating culture one month after start of incubation. Batch bottles with Treatment 3 were terminated after complete ethene production was achieved on Day 105. Monitoring of all columns commenced after a short stabilization period on Day 16. 

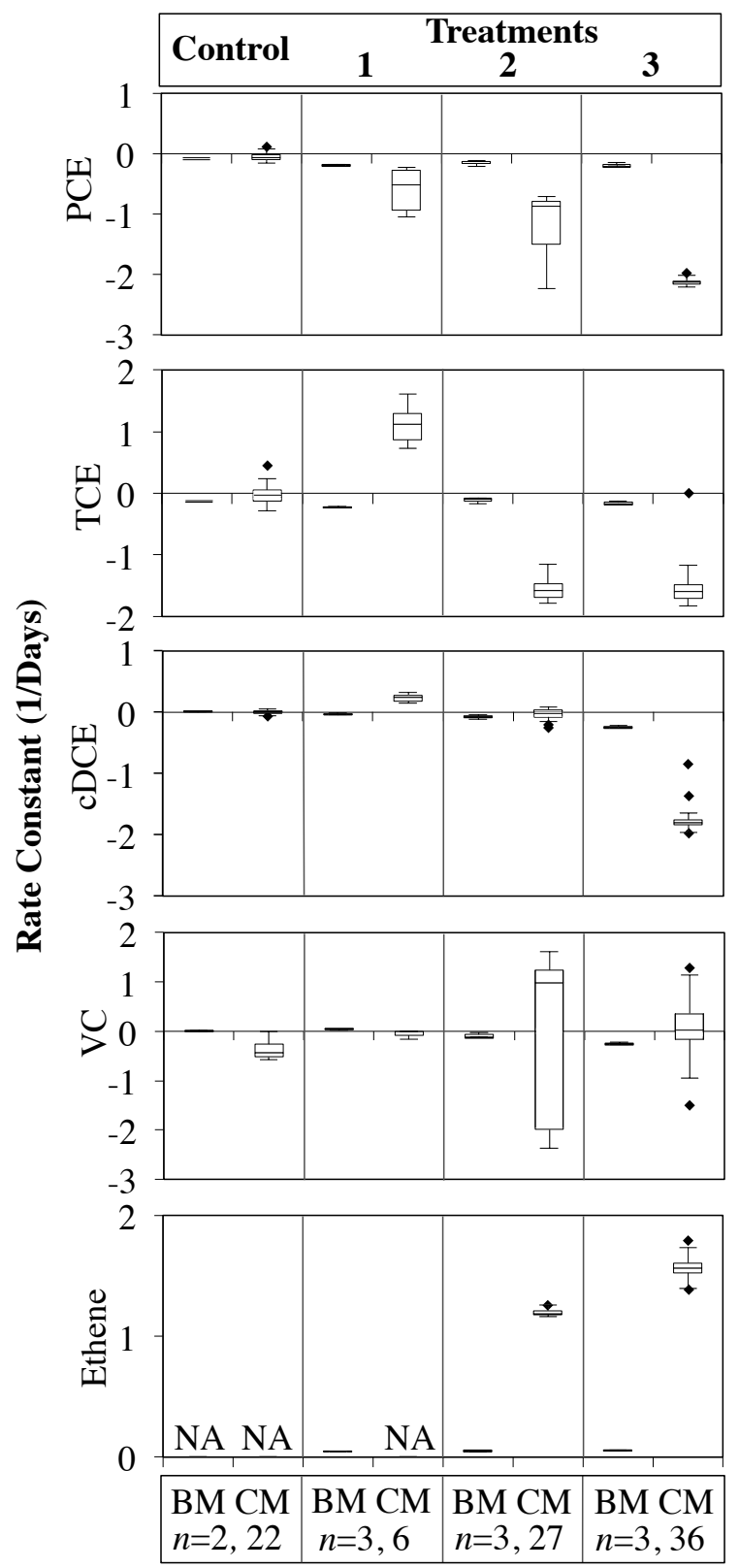

$$
\begin{aligned}
& \text { 1.5*IQR } \quad \mathrm{BM}-\text { Batch Bottles } \\
& \begin{array}{cc}
T_{\text {Median }}^{75} & \text { CM }- \text { Continuous- } \\
& \text { flow Columns } \\
\hline 1.5^{*} \mathrm{IQR} & \bullet-\text { Outlier }
\end{array}
\end{aligned}
$$

Fig. 4. Box plots show first-order rate constants for PCE and its associated degradates in batch and column microcosms. Negative rate constants signify removal of the compound whereas positive rate constants signify compound production. Control batch microcosms yielded only the two data points shown here. Note: NA - Not applicable. 


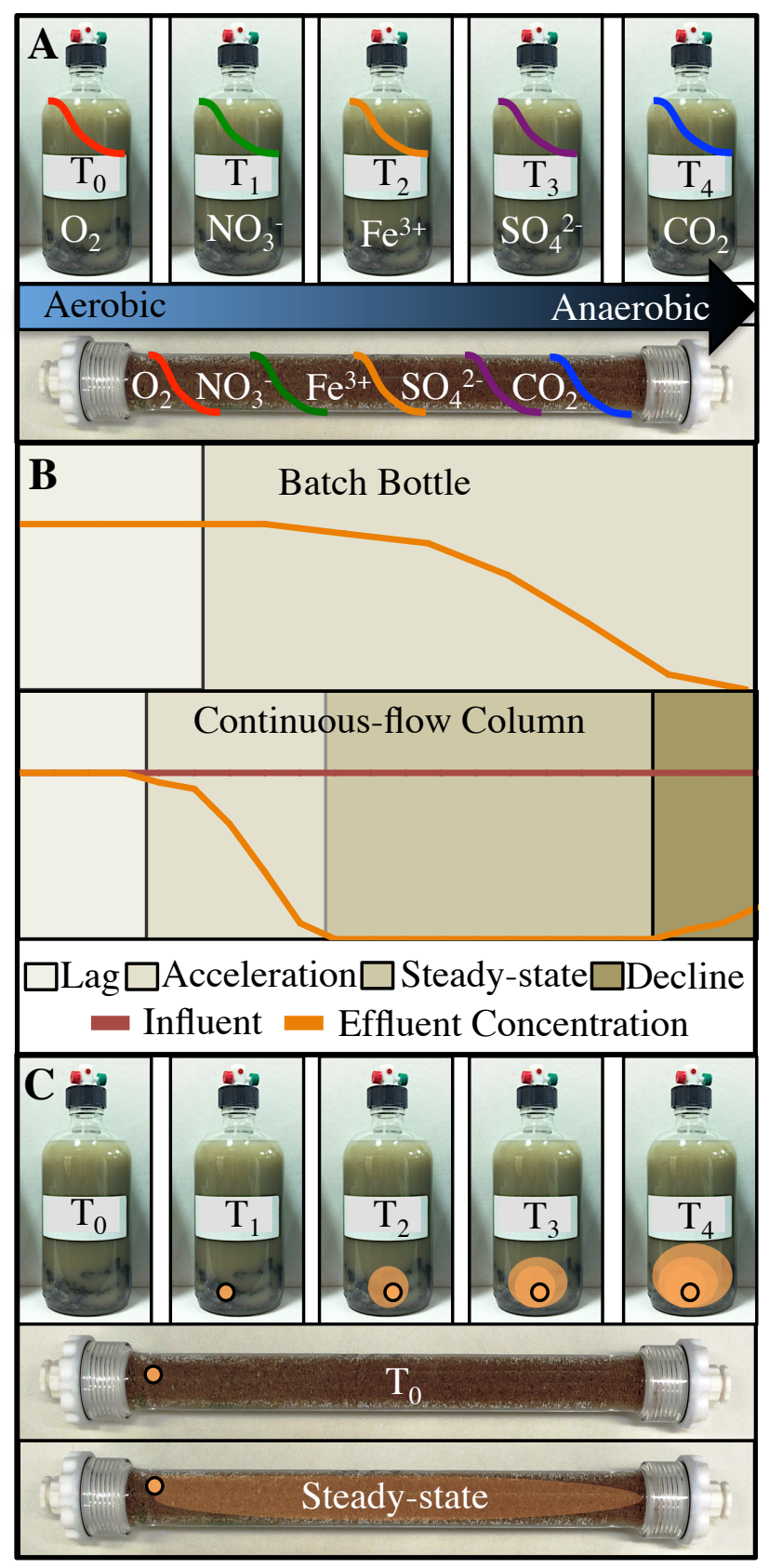

Fig. 5. Illustration of temporal and spatial oxidation-reduction zonation (A), phases of contaminant removal (B), and electron donor distribution (C) in batch bottles and continuousflow columns. Modified from McClellan, 2013 [57]. 
Table 1. Characteristics of batch bottle and continuous-flow column microcosms.

\begin{tabular}{|c|c|c|c|}
\hline Classification & Parameter & Batch Bottles & Columns \\
\hline \multirow{4}{*}{ General } & System Design & Closed & Open \\
\hline & Reducing Conditions & $\begin{array}{l}\text { Unlimited Even When } \\
\text { Initially Aerobic }\end{array}$ & $\begin{array}{l}\text { Limited By Residence } \\
\text { Time When Using } \\
\text { Aerobic Influent } \\
\text { Stream }\end{array}$ \\
\hline & Groundwater & Static & Flow \\
\hline & Contaminant Input & Finite or Pulsed & $\begin{array}{l}\text { Continuous or } \\
\text { Dynamic }\end{array}$ \\
\hline \multirow{4}{*}{$\begin{array}{l}\text { Contaminant } \\
\text { Transformation }\end{array}$} & $\begin{array}{l}\text { Lag Phase } \\
\text { (if present) }\end{array}$ & Visible & Visible \\
\hline & Acceleration Phase & Visible & Visible \\
\hline & $\begin{array}{l}\text { Steady-State } \\
\text { Formation }\end{array}$ & No & Yes \\
\hline & $\begin{array}{c}\text { Amendment } \\
\text { Lifetime Estimate }\end{array}$ & $\begin{array}{l}\text { Limited by Lack of } \\
\text { Flow }\end{array}$ & $\begin{array}{l}\text { Reflective of In Situ } \\
\text { Conditions }\end{array}$ \\
\hline \multirow{2}{*}{$\begin{array}{c}\text { Contaminant } \\
\text { Transformation } \\
\text { Rates }\end{array}$} & $\begin{array}{l}\text { Rate Constant } \\
\text { (Relative) }\end{array}$ & Lower & Higher \\
\hline & $\begin{array}{l}\text { Number of Data } \\
\text { Points Available }\end{array}$ & $\begin{array}{l}\text { Function of Number } \\
\text { of Replicates and Re- } \\
\text { spiking Events }\end{array}$ & $\begin{array}{c}\text { Unlimited Sampling } \\
\text { Opportunities During } \\
\text { Steady-state }\end{array}$ \\
\hline Mass Converted & Total Mass & Lower than CMs & Higher than BMs \\
\hline
\end{tabular}

Notes: BMs- Batch Microcosms, CMs-Column Microcoms. 
Graphical Abstract

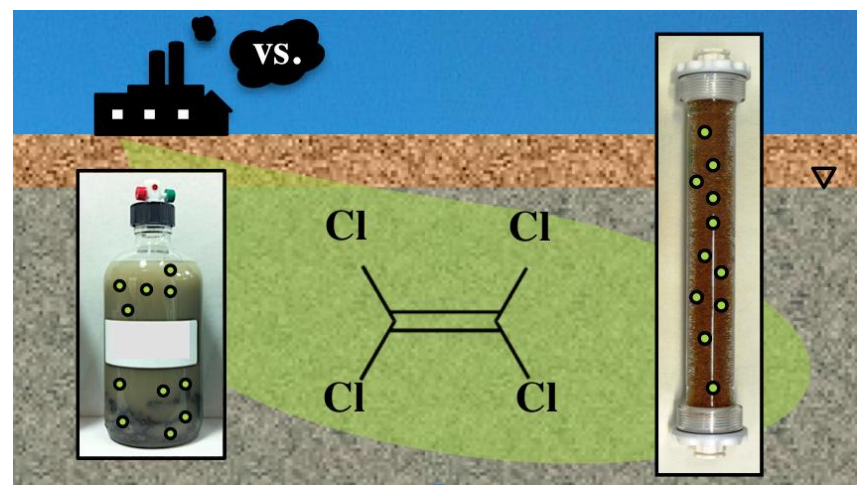

[66] 